\title{
Extensive sequence variation in rice blast resistance gene Pi54 makes it broad spectrum in nature
}

\section{OPEN ACCESS}

Edited by:

Joanna Marie-France Cross,

Inönü University, Turkey

Reviewed by:

Mehboob-ur- Rahman, National Institute for Biotechnology and Genetic Engineering, Pakistan

Swarup Kumar Parida,

National Institute of Plant Genome

Research, India

${ }^{*}$ Correspondence:

Tilak R. Sharma

National Research Centre on Plant Biotechnology, Pusa Campus, LBS

Building, New Delhi-110012, India

trsharma@nrcpb.org;

trsharma1965@gmail.com

${ }^{\dagger}$ Present Address:

Alok Das,

Indian Institute of Pulses Research,

Kanpur, India

Specialty section:

This article was submitted to

Plant Genetics and Genomics,

a section of the journal

Frontiers in Plant Science

Received: 30 January 2015 Accepted: 30 April 2015

Published: 21 May 2015

Citation:

Thakur S, Singh PK, Das A, Rathour

$R$, Variar M, Prashanthi SK, Singh AK, Singh UD, Chand $D$, Singh NK and

Sharma TR (2015) Extensive

sequence variation in rice blast

resistance gene Pi54 makes it broad

spectrum in nature.

Front. Plant Sci. 6:345.

doi: 10.3389/fpls.2015.00345

\author{
Shallu Thakur ${ }^{1,2}$, Pankaj K. Singh ${ }^{1}$, Alok Das ${ }^{1 \dagger}$, R. Rathour ${ }^{3}$, M. Variar ${ }^{4}$, \\ S. K. Prashanthi ${ }^{5}$, A. K. Singh ${ }^{6}$, U. D. Singh ${ }^{6}$, Duni Chand ${ }^{2,}$, N.K. Singh ${ }^{1}$ and \\ Tilak R. Sharma ${ }^{1 *}$ \\ ${ }^{1}$ National Research Centre on Plant Biotechnology, Pusa Campus, New Delhi, India, ${ }^{2}$ Department of Biotechnology, \\ Himachal Pradesh University, Shimla, India, ${ }^{3}$ Department of Agricultural Biotechnology, CSK Himachal Pradesh Agricultural \\ University, Palampur, India, ${ }^{4}$ Central Rainfed Upland Rice Research Station, Central Rice Research Institute, Hazaribagh, \\ India, ${ }^{5}$ School of Agricultural Biotechnology, University of Agricultural Sciences, Dharwad, India, ${ }^{6}$ Indian Agricultural \\ Research Institute, New Delhi, India
}

Rice blast resistant gene, Pi54 cloned from rice line, Tetep, is effective against diverse isolates of Magnaporthe oryzae. In this study, we prospected the allelic variants of the dominant blast resistance gene from a set of 92 rice lines to determine the nucleotide diversity, pattern of its molecular evolution, phylogenetic relationships and evolutionary dynamics, and to develop allele specific markers. High quality sequences were generated for homologs of Pi54 gene. Using comparative sequence analysis, InDels of variable sizes in all the alleles were observed. Profiling of the selected sites of SNP (Single Nucleotide Polymorphism) and amino acids ( $N$ sites $\geq 10$ ) exhibited constant frequency distribution of mutational and substitutional sites between the resistance and susceptible rice lines, respectively. A total of 50 new haplotypes based on the nucleotide polymorphism was also identified. A unique haplotype $\left(H_{-}\right.$3) was found to be linked to all the resistant alleles isolated from indica rice lines. Unique leucine zipper and tyrosine sulfation sites were identified in the predicted Pi54 proteins. Selection signals were observed in entire coding sequence of resistance alleles, as compared to LRR domains for susceptible alleles. This is a maiden report of extensive variability of Pi54 alleles in different landraces and cultivated varieties, possibly, attributing broad-spectrum resistance to Magnaporthe oryzae. The sequence variation in two consensus region: 163 and 144 bp were used for the development of allele specific DNA markers. Validated markers can be used for the selection and identification of better allele(s) and their introgression in commercial rice cultivars employing marker assisted selection.

Keywords: allele mining, Pi54, rice landraces, polymorphism, blast resistance genes, allele specific markers

\section{Introduction}

Blast disease caused by the fungus, Magnaporthe oryzae is one of the most widespread and devastating diseases of rice. Management of rice blast through host resistance is a promising component of the Integrated Disease Management (IDM) programme. Till date, about 101 major rice blast resistance $(R)$ genes have been identified, and 20 of them cloned and characterized (Sharma et al., 2012). Numerous R-genes identified, cloned and characterized are categorized in 
eight classes based on their amino acid motif organization (Sharma et al., 2014). Majority of loci associated with rice blast disease resistance have been reported on chromosome 11 of rice based on genome wide association studies (Wang et al., 2014). Although several blast resistance loci have been identified but only few of them has been employed in breeding for blast management in India (Singh et al., 2011). Further limited success has been realized in durable resistance breeding programmes due to variability of pathogen across locations. Harnessing rice diversity adapted in farmers' fields over the years appears promising alternative to look for resistance source.

Exploring the genetic variants from germplasm (wild and cultivated) is currently being envisaged in many crop species. One of the most widely used methods to identify variants employs polymerase chain reaction (PCR) based techniques to amplify homologs (possible alleles) from the gene pool, known as allele mining. Recently, allele mining for blast resistance has been reported from wild and cultivated species of rice (Yang et al., 2007; Geng et al., 2008; Huang et al., 2008). Studies of Pi-ta gene in rice lines including wild (AA and CC genome) and cultivated species indicated consensus conserved sequence before divergence (Wang et al., 2008). In another study, Pi-ta orthologs from 26 accessions (Oryza rufipogon, O. sativa, $O$. meridionalis, and $O$. officinalis), collected from 10 different countries highlighted dimorphic pattern of nucleotide polymorphism and low nucleotide diversity at the LRD region (Yoshida and Miyashita, 2009). In similar lines, the allelic variants and flanking sequences of $\mathrm{Pi}$-ta have been studied in 159 geographically diverse accessions of Oryza species (AA genome) (Lee et al., 2009). The Pi-ta alleles also have been studied extensively in Indian landraces (Thakur et al., 2013b). Other blast resistance loci like Pid3, Pi9 and Piz(t) has been explored to study the nucleotide polymorphism and evolutionary pressure (Shang et al., 2009; Liu et al., 2011; Thakur et al., 2013a). However, such detailed analysis is lacking for the important blast resistance gene, Pi54 that confers broad spectrum resistance to blast disease (Sharma et al., 2010). The Pi54 gene located on chromosome 11 having unique zinc finger domain, besides LRR domain (Sharma et al., 2005a,b; Gupta et al., 2012). Functional complementation indicated that this gene provides stable and high level of resistance against geographically diverse strains of $M$. oryzae, collected from different parts of India (Rai et al., 2011). The gene possibly triggers up-regulation of defense response genes (callose, laccase, PAL, and peroxidase), transcription factors (NAC6, Dof Zinc finger, MAD box, bZIP, and WRKY) that fortify cell wall/plasmodesmata leading to hypersensitive response, and affecting resistance reaction (Gupta et al., 2011). Currently, the gene is being used in enhanced blast resistant breeding programme (Singh et al., 2011). An ortholog of Pi54 gene from wild species of rice has also been recently cloned and functionally validated (Das et al., 2012). However, the allelic variants of Pi54 gene have not been characterized from rice landraces, that are believed to have co-evolved with pathogen, and hence represents better "evo-devo" perspective of resistance reaction.

Till date, cultivated and wild species of rice have been employed for prospecting novel variants of blast resistance genes. Landraces too represents unmatched genetic potential for rice improvement. The local landraces or local rice varieties are genetically diverse, balanced population and are in equilibrium with the environment and pathogens, in contrast to the rice varieties. Unlike high yielding varieties, the landraces are endowed with tremendous genetic variability, as they are not subjected to subtle selection over a long period of time. Probably, it helps landraces to adapt in wide agro-ecological niches with unmatched qualitative traits, medicinal properties and important genetic resources for resistance to pests and diseases. Owing to their specific domination in geo-graphical niches, landraces have genes of resistance to biotic stresses, which have not been widely utilized or incorporated into modern varieties (Ram et al., 2007). The landraces grown in rice blast "hot- spots" of the Indian subcontinent has remained largely unexplored. Molecular markers linked to major $R$-genes represent an important tool for marker assisted selection (MAS) (Costanzo and Jia, 2010). Variations in terms of Single Nucleotide Polymorphisms (SNPs) and insertiondeletions (InDels) covering the entire genic segment can be compared among genotypes to identify functional markers to aid the selection process. Markers associated with two cloned blast $R$ genes ( $P i-b$ and $P i$-ta) as well as a PCR-based SNP markers for Piz locus and Pik locus (Hayashi et al., 2004; Jia et al., 2009; Zhai et al., 2011) are to mention a few. Conventional breeding with MAS would therefore, benefit from the development of new $R$ gene specific markers, which would allow pyramiding of multiple genes in adapted germplasm toward realizing broader spectrum disease resistance. Molecular population genetic analysis of local landraces and cultivated varieties might provide insight on the selection forces maintaining resistance and preventing evolution of new specificities in natural pathogen populations. Therefore, this study was conducted with objectives, (i) analysis of variants of Pi54 alleles from the cultivated varieties and Indian landraces of rice collected from different eco-geographical regions (ii) structural analysis of Pi54 alleles to understand molecular evolution at the loci, and (iii) development of allele specific functional markers for use in marker assisted selection.

\section{Materials and Methods}

\section{Plant Material and Fungal Culture}

A set of 92 rice lines (landraces and cultivated varieties) were selected from different geographic locations of India for prospecting of Pi54 alleles. The diagnostic isolate of M. oryzae (Mo-nwi-37-1) was used for the phenotypic evaluation of all the rice lines (Rai et al., 2011; Rathour et al., unpublished data).

\section{Preparation of Fungal Culture}

Fungal culture of Mo-nwi-37-1 was maintained on Oat Meal Agar (HiMedia, India) medium in pre-sterilized pertiplates (90 mm diameter). For sporulation, the culture was multiplied in Mathur's medium (Dextrose $8 \mathrm{~g} / \mathrm{L}$, Magnesium sulfate $2.5 \mathrm{~g} / \mathrm{L}$, Potassium phosphate $2.75 \mathrm{~g} / \mathrm{L}$, Neo-Peptone $2.5 \mathrm{~g} / \mathrm{L}$, Yeast Extract $2.0 \mathrm{~g} / \mathrm{L}$, and agar $16 \mathrm{~g} / \mathrm{L}$ ). The culture plates were maintained at $22^{\circ} \mathrm{C}$ for $12-16$ days under constant illumination with white fluorescent light $(55 \mu \mathrm{F} / \mathrm{Em} / \mathrm{s})$. For the preparation of fungal spores, $5 \mathrm{ml}$ of $0.2 \%$ gelatine solution was added to individual plate on agar surface and gently rubbed with scrapper to separate conidia from the conidiophores. The spore 
concentration was brought to approximately $10^{5} \mathrm{spores} / \mathrm{ml}$. The seedlings were sprayed with spore suspension of about $1 \mathrm{ml}$ per plant at 2-3 leaf stage.

\section{Inoculation of Rice Lines with Diagnostic $M$. oryzae Isolate}

Rice lines were grown in plastic pots (12 inch dia.) containing sterilized potting mixture in the rice blast testing facility, NRCPB, IARI, New Delhi. Rice lines, Tetep, and Taipei 309 were used as positive and negative controls, respectively. Physical parameters were set for $16 \mathrm{~h} / 8 \mathrm{~h}$ light-dark photoperiod. The day and night temperatures were maintained at $25^{\circ} \mathrm{C}$ and $21^{\circ} \mathrm{C}$, respectively, with relative humidity $(\mathrm{RH})$ of more than $90 \%$. All the seedlings assessed in the experiment were sprayed simultaneously with $M$. oryzae spore suspension of $10^{5}$ spores $/ \mathrm{ml}$. Disease reaction was recorded after 7 days of inoculation using 0-5 disease assessment scale (Bonmann et al., 1986). Where, $0=$ No evidence of infection; $1=$ Brown specks smaller than $0.5 \mathrm{~mm}$ in diameter, no sporulation; $2=$ Brown specks about $0.5-1.0 \mathrm{~mm}$ in diameter, no sporulation; $3=$ Roundish to elliptical lesions, $1-3 \mathrm{~mm}$ in diameter, gray center surrounded by brown margins, lesions capable of sporulation; $4=$ Typical spindle shaped blast lesions capable of sporulation, $3 \mathrm{~mm}$ or longer; $5=$ lesions as in 4 but about half of 1-2 leaf blades killed by coalescence of lesions. Reaction types $0,1,2$, and 3 were considered resistant, while 4 and 5 considered as susceptible.

\section{PCR Amplification and Sequencing}

Genomic DNA was extracted from fresh leaves of selected rice lines using the modified Cetyltrimethyl Ammonium Bromide (CTAB) method of DNA isolation (Murray and Thompson, 1980). For PCR amplification, nucleotide sequence of the blast resistance gene Pi54 (Loc_Os11g42010) was retrieved from NCBI database (www.ncbi.nlm.nih.gov/). Overlapping oligos Pi54_F1 (CAATATAGCTGGGAATTTCAGAGG) and Pi54_R1 (AGATAATGTGTTTGTCTGGCTGTC); Pi54_F2 (CATGAA CAGAGCACTGATGACATA) and Pi54_R2 (GGATAACAA GCACTGAGCCATATC); Pi54_F3 (CCGTTCTGACCATAG AAATTATCG) and Pi54_R3 (GTGCAATTACATAAGCTA GACCTTG) were designed using Primer 3 software (Rozen and Skaletsky, 2000) to amplify $1.5 \mathrm{~kb}$ region using primer walking technique. PCR was performed with genomic DNA isolated from rice landraces and cultivated varieties using Pfu polymerase (FINNZYMES OY, Keilaranta, Espoo, Finland) with the following thermal cycling conditions: initial DNA denaturation at $95^{\circ} \mathrm{C}$ for $2 \mathrm{~min}$ followed by 30 cycles of $95^{\circ} \mathrm{C}$ for $30 \mathrm{~s}, 58^{\circ} \mathrm{C}$ (Pi54_F1 and Pi54_R1; Pi54_F2 and Pi54_R2) or $60^{\circ} \mathrm{C}$ (Pi54_F3 and Pi54_R3) for $30 \mathrm{~s}, 72^{\circ} \mathrm{C}$ for $1 \mathrm{~min}$, final elongation at $72^{\circ} \mathrm{C}$ for $10 \mathrm{~min}$ and hold at $4^{\circ} \mathrm{C}$. The PCR derived amplification products were used as template for determining DNA sequences using Sanger's dideoxy method of sequencing.

\section{Sequencing of PCR Amplicon}

The purified PCR amplicon was sequenced according to manufacturer's instruction directly by using modified Sanger's dideoxy terminator cycle sequencing chemistry on an automated capillary-based DNA sequencer (ABI 3730xl DNA Analyzer) in both forward and reverse direction twice using amplified product specific primers. The PCR products were run in a cycle sequencing reaction with thermal cycling conditions as 30 cycles of denaturation $\left(95^{\circ} \mathrm{C}\right.$ for $\left.20 \mathrm{~s}\right)$, annealing $\left(60^{\circ} \mathrm{C}\right.$ for $\left.20 \mathrm{~s}\right)$, and extension $\left(60^{\circ} \mathrm{C}\right.$ for $\left.4 \mathrm{~min}\right)$ followed by hold at $4^{\circ} \mathrm{C}$. The purified sequencing products were resolved on a capillary-based automated DNA sequencer (ABI 3730xl DNA Analyzer). Full length sequence reads were obtained by assembly of multiple reads of each fragment using Phred/Phrap and Consed software (Ewing and Green, 1998). Each fragment was sequenced at least four times and high quality (Phred 20) consensus sequence was used for data analysis.

\section{Analysis of Sequenced Pi54 Alleles}

The sequenced data were aligned using ClustalW 2.0 (Larkin et al., 2007) at their default alignment parameters and manually corrected by MEGA 4.0. Gene coding regions were predicted with FGENESH (Solovyev et al., 2006) using the original Pi54 (Tetep) sequence as a reference. The LRR domain was identified as described earlier (Sharma et al., 2005a). Motif was identified using motif scan software (http://hits. isb-sib.ch/cgi-bin/PFSCAN) and SMART tool (http://smart. embl-heidelberg.de/). Phylogenetic analysis was performed with MEGA 4.0 using the Neighbor-Joining method (Saitou and Nei, 1987). The bootstrap consensus tree inferred from 1000 replicates was used to represent the evolutionary history of the taxa analyzed (Felsenstein, 1985). Branches corresponding to partitions reproduced in less than $50 \%$ bootstrap replicates were collapsed. The tree was drawn to scale, with branch lengths in the same units as those of the evolutionary distances used to infer the phylogenetic tree. The evolutionary distances were computed using the Maximum Composite Likelihood method (Tamura et al., 2004) and were depicted in the units of the number of base substitutions per site. All positions containing gaps and missing data were eliminated from the dataset (Complete deletion option). Analysis of overall transition: transversion ratio, variable, and parsimony informative positions were calculated using MEGA 4.0 software (Tamura et al., 2007).

The DnaSP 5.10 software was used for the analysis of nucleotide polymorphism (Rozas et al., 2003). The aligned DNA sequences were imported into the DnaSP software to calculate $S$ (number of polymorphic or segregating sites), $\pi$ (nucleotide diversity), $\theta$ (Theta from $S$, Theta-W), and $D$ (Tajima's D), and to draw the sliding window of nucleotide diversity $(\pi)$. Haplotype networks were constructed for each potential SNP's sites by statistical parsimony with the software TCS 1.21 (Templeton et al., 1992; Clement et al., 2000). The networks were assembled based on an absolute distance matrix between haplotypes, i.e., the number of mutations separating each haplotypes, with a parsimony probability of 95\%. Haplotype diversity (Hd) was analyzed between disease resistance and susceptible phenotypes of Oryza species. The DnaSP 5.10 program (Rozas et al., 2003) was used for the analysis of haplotype diversity Hd (Nei, 1987).

\section{Development of Functional Markers}

The PCR-based co-dominant and dominant STS (sequence tagged site) markers targeting consensus InDels of 144 and 
$163 \mathrm{bp}$, respectively were designed. In case of dominant marker, the forward primer (DPi54_163F) was designed flanking to the insertion (163 bp) and reverse primer (DPi54_163R) was designed from the sequence of insertion. The forward (CPi54_144F) and reverse (CPi54_144R) primers in case of codominant markers were designed from the flanking regions of 144 bp insertion. Primer pairs [CPi54_144F (AAGTACTTCAT GATCTATTCTACTGG) and CPi54_144R (CCGTTCTGACC ATAGAAATTATCG)]; DPi54_163F (ACCATGACTAGCTATG AAAAATCT) and DPi54_163R (AGAATAGATCATGAAGTA CTTGAAAC)] were designed by using Primer 3 software (Rozen and Skaletsky, 2000). PCR amplification was carried out on programmable Thermal Cycler (BioRad, Washington DC, USA) using the following temperature profile: initial DNA denaturation, $95^{\circ} \mathrm{C}$ for $2 \mathrm{~min}$; followed by 35 cycles of denaturation, $94^{\circ} \mathrm{C}$ for $20 \mathrm{~s}$; annealing, $55^{\circ} \mathrm{C}$ (DPi54_163F and DPi54_163R) or $58^{\circ} \mathrm{C}\left(\mathrm{CPi} 54 \_144 \mathrm{~F}\right.$ and $\left.\mathrm{CPi} 54 \_144 \mathrm{R}\right)$ for $30 \mathrm{~s}$; extension, $72^{\circ} \mathrm{C}$ for $1 \mathrm{~min}$; and final extension at $72^{\circ} \mathrm{C}$ for $10 \mathrm{~min}$ and then hold at $4^{\circ} \mathrm{C}$ using Taq DNA polymerase (Vivantis, USA). The PCR amplified product was resolved in $2 \%$ agarose gel using 1.0X TAE buffer.

\section{Results}

\section{Phenotypic Evaluation of Rice Landraces}

The rice lines (92) used in present study were grown in contained condition and the 15 days-old-seedlings were challenged with representative $M$. oryzae isolate, Mo-nwi-37-1. After a week of inoculation, all the rice lines were grouped into resistant and susceptible categories based on their reaction to $M$. oryzae. Out of 92 rice lines, 72 were found resistant and the rest 20 susceptible, based on disease assessment scale (Bonmann et al., 1986) (Table S1). These lines were used for the allele mining studies of Pi54 gene.

\section{Nucleotide Polymorphism}

To determine the nucleotide diversity at the Pi54 locus in rice lines, $1.5 \mathrm{~kb}$ long fragments were amplified from 92 rice lines and sequenced using 3 different overlapping primer combinations (Figure 1). All the fragments were sequenced and high quality ( $>$ Phred 20 ) assembled sequence of each allele has been deposited in the EMBL database (Table S1). For sequence analysis, the Pi54 alleles were grouped into three different categories: (i) phenotypes: resistant and susceptible (ii) landraces and cultivated varieties; (iii) indica and japonica types (Table 1). Nucleotide variations were high in the genic region of Pi54 allele. A total of 197 SNPs, large insertions of 38, 49, 144, and 163 bps and single base pair deletions were identified in the Pi54 alleles.

We calculated percentage of mutational change with respect to the reference Pi54 gene and compared within and between disease resistance and susceptible alleles of Oryza species. All mutational changes were scored for the specific positions only. The number of mutations per site was found to be equal to and greater than 10 (i.e., $\mathrm{N}_{\text {mut }} \geq 10$ ). Overall, 40 mutational sites were identified across the alignment, out of which 27 are transitions (ti) and 12 transversion (tv) (Table S2).

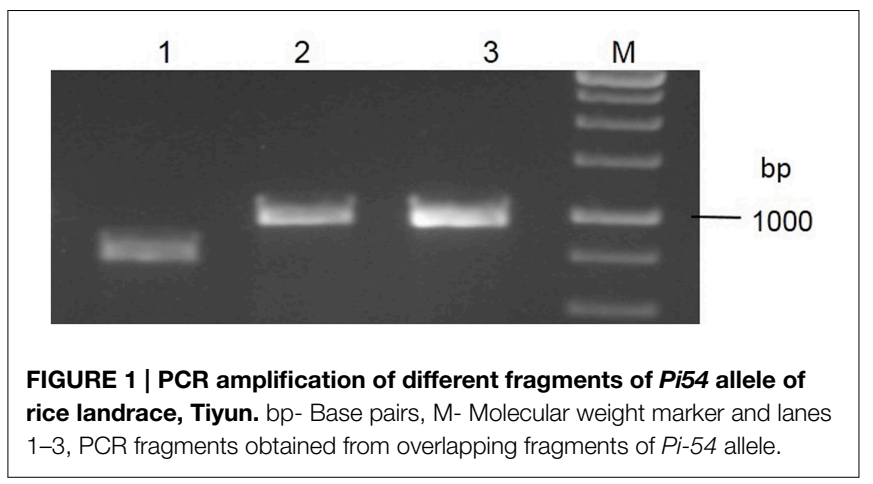

TABLE 1 | Different groups and rice accessions used in mining for blast resistance gene Pi54.

\begin{tabular}{llc}
\hline Group & Species & No. of accessions \\
\hline Cultivar & O. sativa indica & 48 \\
& O. sativa japonica & 3 \\
Landrace & O. sativa indica & 32 \\
& O. sativa japonica & 3 \\
Breeding line & O. sativa aus & 2 \\
Hybrid & O. sativa indica & 2 \\
Unknown & O. sativa indica & 1 \\
& O. sativa indica & 1 \\
\hline
\end{tabular}

Further, mutational profiling of disease resistance and susceptible phenotypes of Oryza species was constructed in all alleles mined from 92 rice landraces. It was found that $61 \%$ of mutational sites have mutations at one site, $18 \%$ of the sites have mutations at twonine sites and rest of the $21 \%$ sites have mutation at 10 or more than 10 sites (Figure 2A). Most of the mutational sites exhibited a constant frequency distribution between the resistance and susceptible groups (Figure 2B).

The Pi54 alleles of landraces harbor substantially higher polymorphism as compared to the Pi54 alleles of cultivated species, because of heterogeneous nature of rice landraces used in present study, which might have accumulated more mutations during the course of evolution. The nucleotide diversity was high in the Pi54 alleles of resistant lines compared to the Pi54 alleles of susceptible lines (Table 2). The Pi54 alleles of indica and japonica species were almost equally diverse at nucleotide level. Higher nucleotide variation at the resistant loci is possibly due to interaction with highly avirulent and frequently mutating avirulent strains of M. oryzae. Overall, a total of 198 polymorphic sites excluding InDels, were identified in the $1.5 \mathrm{~Kb}$ region of Pi54 alleles. Maximum (225) polymorphic sites were identified in the Pi54 alleles isolated from Indian landraces; however, very less diversity was obtained in the alleles cloned from japonica species (Table 2). Average pair wise nucleotide diversity $(\pi)$ and Watterson's nucleotide diversity estimator $\left(\theta_{\mathrm{w}}\right)$ over the Pi54 alleles in susceptible rice lines $\left(\pi=0.0208\right.$ and $\theta_{\mathrm{w}}=$ 0.01916) was lowest among all other Pi54 alleles included in the present study. Within the groups, the nucleotide diversity was lowest in Pi54 alleles of cultivated varieties $(\pi=0.02254$ 
A
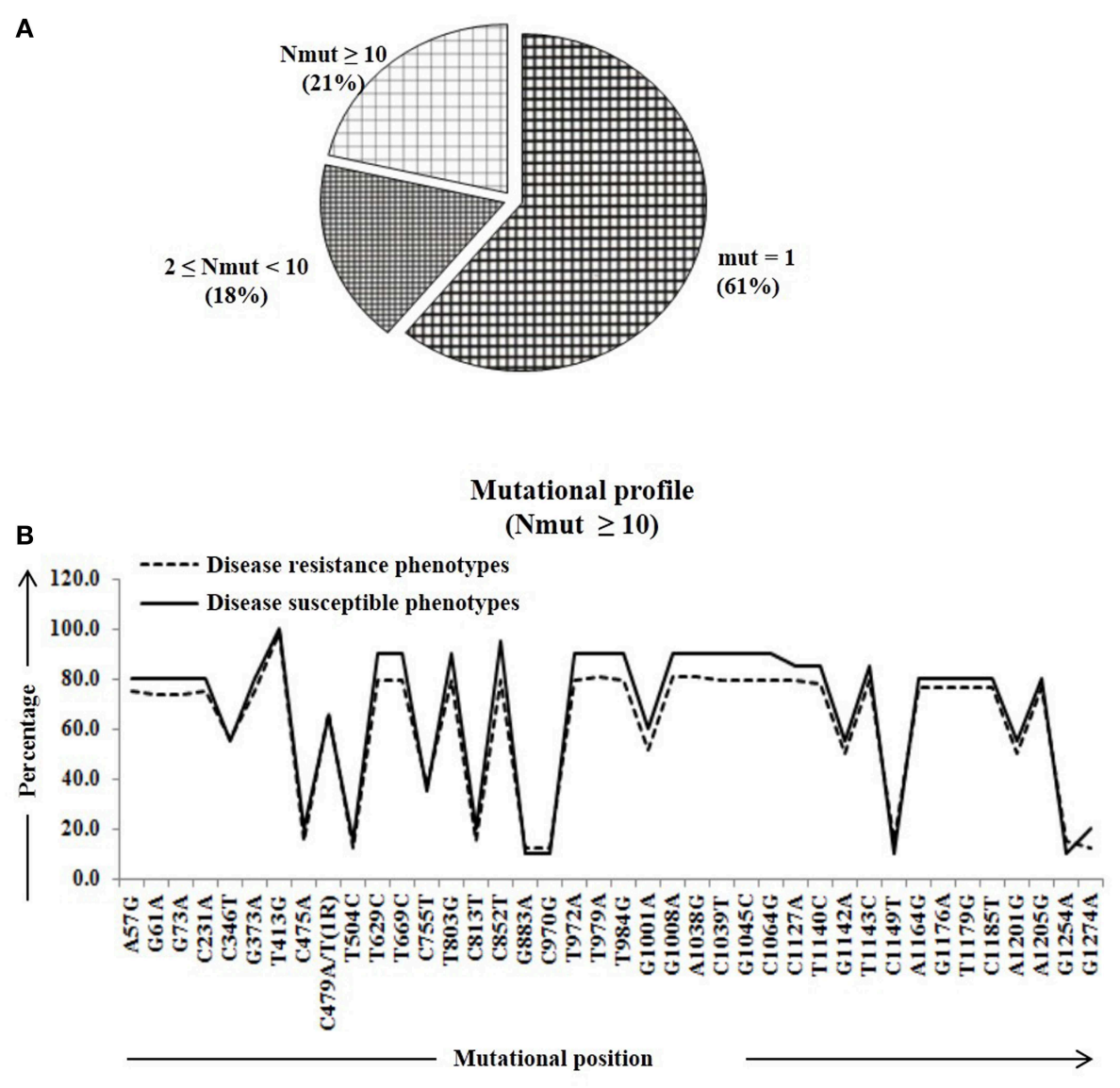

FIGURE 2 | The number of amino acid substitutions in the predicted 64 Pi54 protein. (A) Distribution of amino acid substitutions across 64 predicted proteins. (B) Substitutional profile of amino acids of disease resistant and susceptible phenotype.

and $\left.\theta_{\mathrm{w}}=0.02102\right)$ compared to landraces $(\pi=0.03417$ and $\theta_{\mathrm{w}}=0.03877$ ). Among the Pi54 alleles of indica and japonica species, diversity was low in the alleles of japonica species (Table 2). The LRR domain harbors substantial diversity, explaining the selection pressure it underwent. Higher diversity was observed in LRR domain of japonica species as compared to others (Figure 3).

\section{Phylogenetic Relationship between the Alleles}

Phylogenetic tree constructed based on Pi54 allelic sequences obtained from 92 accessions resulted in two major clusters (Figure 4). Both the clusters were further divided into separate sub-clusters but species specific clustering was not obtained. Similarly, separate phylogenetic tree was also constructed for the Pi54 alleles derived from resistant and susceptible lines. All the resistant Pi45 orthologs were grouped into three clusters (Figure 4A). Cluster I and II were further divided into two sub-clusters, i.e., $\mathrm{I}_{\mathrm{A}}, \mathrm{I}_{\mathrm{B}}$, and $\mathrm{II}_{\mathrm{A}}, \mathrm{II}_{\mathrm{B}}$. The sub-cluster $\mathrm{I}_{\mathrm{A}}$ and cluster III consisted of all the resistance alleles belonging to indica group whereas all other sub-clusters included alleles of indica as well as japonica groups. The Pi54 alleles from susceptible lines were grouped into two major distinct clusters (Figure 4B).

\section{Pattern of Molecular Evolution}

A haplotype network was constructed to identify mutational changes, based on potential SNPs of all Pi54 alleles isolated from 92 rice lines. We identified fifty new haplotypes from the nucleotide polymorphism of the Pi54 alleles. To determine the linkage among these haplotypes, a haplotype network was constructed (Figure 5). In this network, 50 haplotypes were clustered in five major haplogroup (major haplogroup contain three or more Pi54 alleles) and the rest as minor haplogroups. We identified resistant phenotype specific haplotype (H_3) and rest of the major haplotypes contained alleles from resistant and susceptible lines as well. Furthermore, haplotype, H_4 was the only mixed haplotype consisted of the Pi54 alleles of indica, japonica and aus rice accessions. Similar haplotype network has been constructed for resistant as well susceptible Pi54 alleles. In case of resistance alleles, total number of identified haplotypes was 41 which clustered into five major haplogroups (Figure S1). All the major haplogroups consisted of Pi54 alleles isolated from indica rice lines. Total number of 14 haplotypes identified in Pi54 alleles was from susceptible rice lines and were, clustered into four major haplogroups (Figure S2). The major haplogroup of these rice lines consisted of Pi54 alleles of Indica rice lines except for $\mathrm{H} 1$ which is a mixed cluster of alleles from both 
TABLE 2 | Nucleotide polymorphism of the Pi54 alleles mined from different accessions of rice.

\begin{tabular}{|c|c|c|c|c|c|c|c|c|c|}
\hline Group & Elements & Position (nt) & $\mathbf{S}$ & $\pi$ & $P(\pi)$ & $\Theta$ & $P(\Theta)$ & Tajima's D & $\mathrm{Ka} / \mathrm{Ks}$ \\
\hline \multirow[t]{3}{*}{ All } & Whole sequence & [1-4194] & 198 & 0.0226 & 0.00146 & 0.02972 & 0.00801 & -1.07559 & $<1$ \\
\hline & CDS & [1338-3585] & 163 & 0.02541 & 0.0018 & 0.03289 & 0.00893 & -1.03898 & $<1$ \\
\hline & LRR & [3324-3462] & 15 & 0.01073 & 0.00218 & 0.0235 & 0.00847 & -1.70363 & $>1$ \\
\hline \multirow[t]{3}{*}{ O. sativa indica } & Whole sequence & [1-4194] & 179 & 0.02245 & 0.00131 & 0.02717 & 0.00753 & -0.87382 & $<1$ \\
\hline & CDS & [1338-3585] & 140 & 0.02431 & 0.00149 & 0.029 & 0.00811 & -0.86041 & $<1$ \\
\hline & LRR & [3324-3462] & 9 & 0.00839 & 0.00123 & 0.01451 & 0.00607 & -1.34456 & $>1$ \\
\hline \multirow[t]{3}{*}{ O. sativa japonica } & Whole sequence & {$[1-4194]$} & 77 & 0.0238 & 0.00487 & 0.02285 & 0.01094 & -0.06202 & $<1$ \\
\hline & CDS & [1338-3585] & 68 & 0.02899 & 0.00632 & 0.02815 & 0.01352 & -0.08869 & $<1$ \\
\hline & LRR & [3324-3462] & 9 & 0.02815 & 0.01044 & 0.0292 & 0.01615 & -0.21398 & $>1$ \\
\hline \multirow[t]{3}{*}{ Cultivar } & Whole sequence & [1-4194] & 123 & 0.02254 & 0.00144 & 0.02102 & 0.00646 & -0.08589 & $<1$ \\
\hline & CDS & [1338-3585] & 106 & 0.02576 & 0.00176 & 0.02431 & 0.00752 & -0.14919 & $<1$ \\
\hline & LRR & {$[3324-3462]$} & 7 & 0.00883 & 0.00153 & 0.01259 & 0.00587 & -1.13434 & $>1$ \\
\hline \multirow[t]{3}{*}{ Landrace } & Whole sequence & {$[1-4194]$} & 225 & 0.03417 & 0.00467 & 0.03877 & 0.01246 & -0.94232 & $<1$ \\
\hline & CDS & [1338-3585] & 141 & 0.02451 & 0.00371 & 0.03502 & 0.01139 & -1.36704 & $<1$ \\
\hline & LRR & {$[3324-3462]$} & 13 & 0.01247 & 0.00461 & 0.02524 & 0.01036 & -1.72346 & $>1$ \\
\hline \multirow[t]{3}{*}{ Disease resistance phenotypes } & Whole sequence & [1-4194] & 192 & 0.0237 & 0.00171 & 0.03004 & 0.00848 & -0.9818 & $<1$ \\
\hline & CDS & [1338-3585] & 158 & 0.0267 & 0.00215 & 0.03366 & 0.00957 & -0.96141 & $<1$ \\
\hline & LRR & {$[3324-3462]$} & 15 & 0.01213 & 0.00267 & 0.02481 & 0.00917 & -1.67675 & $>1$ \\
\hline \multirow[t]{3}{*}{ Disease susceptible phenotypes } & Whole sequence & [1-4194] & 87 & 0.0208 & 0.00286 & 0.01916 & 0.00728 & 0.27313 & $<1$ \\
\hline & CDS & [1338-3585] & 71 & 0.02208 & 0.00327 & 0.02104 & 0.00806 & 0.15424 & $<1$ \\
\hline & LRR & [3324-3462] & 3 & 0.0057 & 0.00174 & 0.00699 & 0.00454 & -0.56505 & $>1$ \\
\hline
\end{tabular}

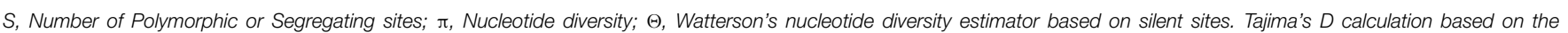

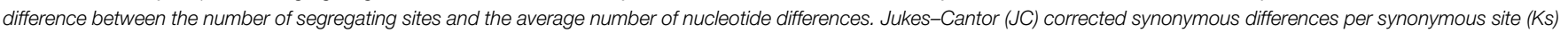
and non-synonymous differences per non-synonymous site (Ka). For Tajima's $D$, no value is significant at 0.10 level $(P>0.10)$ and $0.10>P>0.05$ (for bold).

indica and japonica lines. Statistically high haplotypes diversity $(0.935 / 0.019)$ was observed within the studied data set of 92 Pi54 alleles of Oryza species. In case of susceptible and resistant alleles, high haplotypes diversity $(0.958 / 0.028)$ was observed in disease susceptible Pi54 alleles of Oryza species than resistance (0.935/0.019) alleles (Table 3).

In present study, sequence analysis indicated variable number (0-3) of Open Reading Frames (ORFs) in the Pi54 locus, with exception of 28 rice lines where no ORF was detected. Absence of ORF in these sequences might be due to reshuffling or recombination events of the locus resulting in absence of start codon or pseodogenized allele, which has lost its function in due course of time. In 40 rice lines, single exon was predicted. However, two and three exons were also predicted in the allelic sequences of 21 and 10 rice lines, respectively (Table S3). This may be due to the creation of new splice sites during the course of evolution. Variation in the number of ORF might have generated based on the selection pressure, it underwent during the evolutionary process. Various insertions have also been identified in the ORFs. The presence of insertion implicates its differential role in regulating disease resistance.

Percentage of substitutional change was calculated at protein level in the Pi54 gene and compared within and between disease resistance and susceptible phenotypes of Oryza species. The amino acid substitutions were scored for the specific positions. The number of substitution per site was found to be equal to and greater than 10 (i.e., $\mathrm{N}_{\text {mut }} \geq 10$ ). Overall, 23 substitutional sites were identified across the alignment of $64 \mathrm{Pi} 54$ proteins (Table S4). The number of mutations per mutational site was calculated in all the aligned 64 predicted sequences implicating $66 \%$ of mutational sites having mutation in one site, $19 \%$ of the sites having mutations in two to nine sites and rest of the $15 \%$ sites having mutation in 10 or more than 10 sites (Figure 6A). The mutational profiling of disease resistance and susceptible phenotypes of Oryza species indicated that most of the mutational sites were showing a constant frequency distribution between the resistance and susceptible groups (Figure 6B).

The nucleotide sequences of all the Pi54 alleles were translated and the predicted proteins ranged between 73 and 486 amino acid residues having many predicted functional domains. The Zinc-finger domain $(\mathrm{ZnF})$ was predicted in all the $\mathrm{Pi} 54$ proteins except for a few (Figure S3). The sequence of predicted $\mathrm{ZnF}$ domain was highly conserved (100\% similarity) in all the Pi54 proteins (Figure S3). Important motifs identified in the translated sequences of the Pi54 alleles are N-glycosylation sites, 


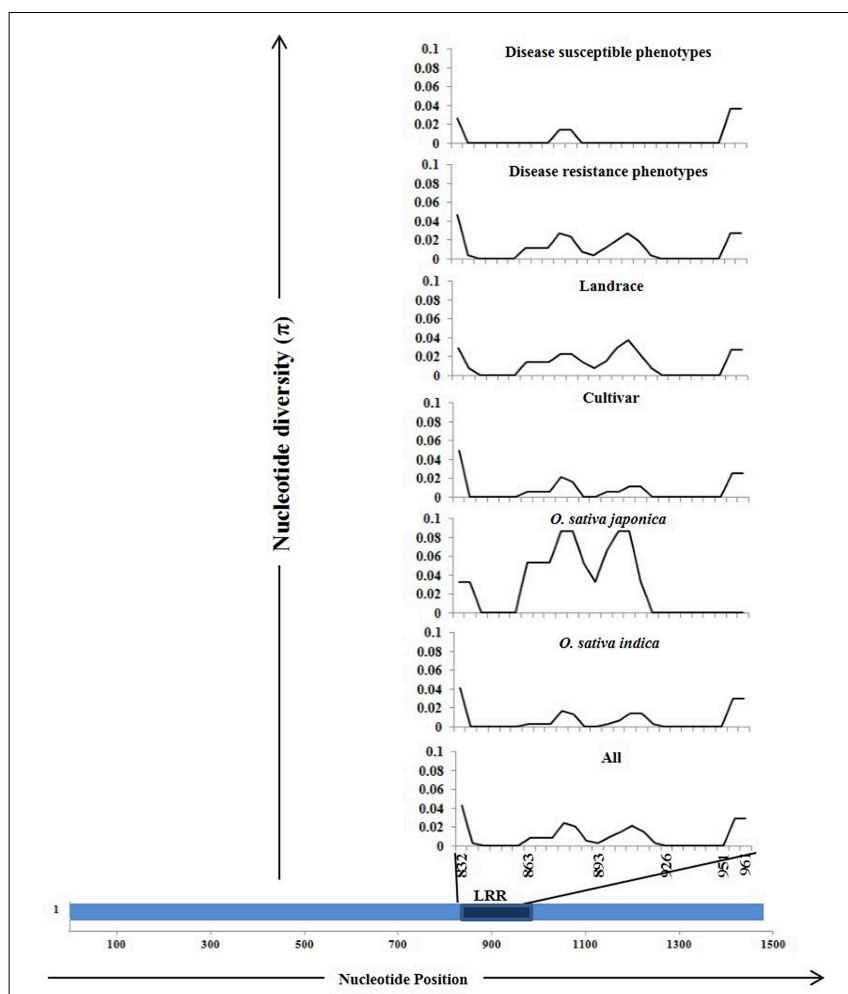

FIGURE 3 | Sliding window analysis of nucleotide diversity $(\pi)$ in the LRR domains of $\mathbf{9 2} \mathbf{P i 5 4}$ alleles. The different groups from where the alleles were mined are given above in the Figure. The nucleotide diversity $(\pi)$ was plotted on $\mathrm{Y}$-axis and the $\mathrm{X}$-axis represents the positions of nucleotides.

phosphorylation (kinase C phosphorylation site, casein kinase II phosphorylation site, tyrosine kinase phosphorylation site), tyrosine sulfation site, $\mathrm{N}$-myristoylation site, and leucine zipper (Table S5). These sites were present in variable numbers in all the Pi54 alleles except for tyrosine kinase phosphorylation site and leucine zipper. The presence of phosphorylation sites in Pi54 alleles, indicate their involvement in signal transduction by activating further downstream genes. The presence of $\mathrm{N}$ myristoylation sites in the predicted proteins play important role in membrane anchoring whereas $\mathrm{N}$-glycosylation sites has significant role in protein targeting. Unique leucine zipper was identified in 54 and $73 \%$ of the resistant and susceptible Pi54 proteins, respectively. They are usually found as a part of DNA-binding domain in many transcription factors, and are therefore involved in regulating gene expression. Similarly, tyrosine sulfation sites were also present in 18 and $21 \%$ of the resistant and susceptible Pi54 protein, respectively, which plays important role in strengthening the protein-protein interaction. From above results, it can be concluded that unique Leucine zipper and single tyrosine sulfation sites identified in some of the Pi54 predicted protein sequences which was absent in the reference Pi54 protein.

To evaluate the phylogenetic relationship amongst the predicted Pi54 proteins, neighbor-joining trees were constructed using the LRR regions (Figure S4). All the predicted Pi54 proteins were grouped into three separate clusters of mixed type. This is in contrast to species-specific groups obtained from NBS and LRR domains of Pi9 alleles (Liu et al., 2011).

\section{Analysis of Evolutionary Dynamics}

To test the evolutionary selection dynamics of the Pi54 alleles in 92 Oryza accessions, we evaluated the extent of neutral selection with D statistics (Tajima's D test) (Tajima, 1989). In the present study, Pi54 alleles have been subjected to positive selection [Tajima's D $=-1.07559$ ] for all the alleles and deviating from the model of neutrality (Table 2). It is noteworthy that Pi54 alleles of different groups, such as landraces and cultivated varieties, indica and japonica species, and blast resistant lines have been subjected to positive selection whereas the balancing selection operates in Pi54 alleles of susceptible rice lines [Tajima's D = 0.27313 ]. This might be due to the variable selection pressure acting on the locus, or diverse sample size used in present analysis. Further, coding region of 92 Pi54 alleles and Pi54 alleles of different groups have been analyzed. The value of Tajima's D was negative in the entire coding region $(-1.03898)$ and LRR domain $(-1.70363)$ indicating purifying selection in the CDS and LRR regions (Table 2 ). The ratio of synonymous $\left(k_{s}\right)$ and non-synonymous $\left(k_{\mathrm{a}}\right)$ divergence in whole sequence as well as coding region and parts of the coding region (LRR domains) was calculated in all the 92 Pi54 alleles and separately for the Pi54 alleles from different groups (Table 2 ). The value of $\mathrm{k}_{\mathrm{a}} / \mathrm{k}_{\mathrm{s}}$ ratio was used as a criterion for the presence or absence of positive selection for amino acid substitutions. The value of $\mathrm{k}_{\mathrm{a}} / \mathrm{k}_{\mathrm{s}}$ in the whole sequence, coding region of the Pi54 alleles was less than one, indicating low level of polymorphism in these regions, in contrast to high level of polymorphism in LRR domain of all Pi54 alleles as the ratio of $\mathrm{k}_{\mathrm{a}} / \mathrm{k}_{\mathrm{s}}$ was greater than one (Table 2). In the LRR region of the Pi54 alleles of different groups, the value of $\mathrm{k}_{\mathrm{a}} / \mathrm{k}_{\mathrm{s}}$ is greater than one, which indicates that positive directional selection might have favored amino acid substitution in this region. In the present study, LRR region of Pi54 alleles was quite variable and might have role in different recognition specificities, possibly making it more durable.

\section{Development of Allele Specific Markers}

Allele specific DNA markers are important for the introgression of resistant alleles in cultivated rice varieties using marker assisted selection (MAS) strategy. In this study, we developed dominant and co-dominant STS markers based on the large DNA insertions in the allelic sequences of Pi54 alleles. The dominant markers (DPi54_163F and DPi54_163R) were specifically designed to amplify a fragment of 278 bp in resistant Pi54 alleles and absence of band in the susceptible alleles (Figure 7A). By using this marker, we were able to distinguish 22 rice lines having resistant Pi54 allele (presence of 278 bp amplification product) and 15 rice lines having susceptible Pi54 alleles (Table 4). Similarly, codominant marker (CPi54_144F and CPi54_144R) was also tested in a set of rice lines used in present study. PCR amplification with co-dominant markers amplifies fragments of 557 and 313 bp (Figure 7B). The 557 bp fragments were amplified in 10 susceptible rice lines, and a 313 bp band was present in 28 


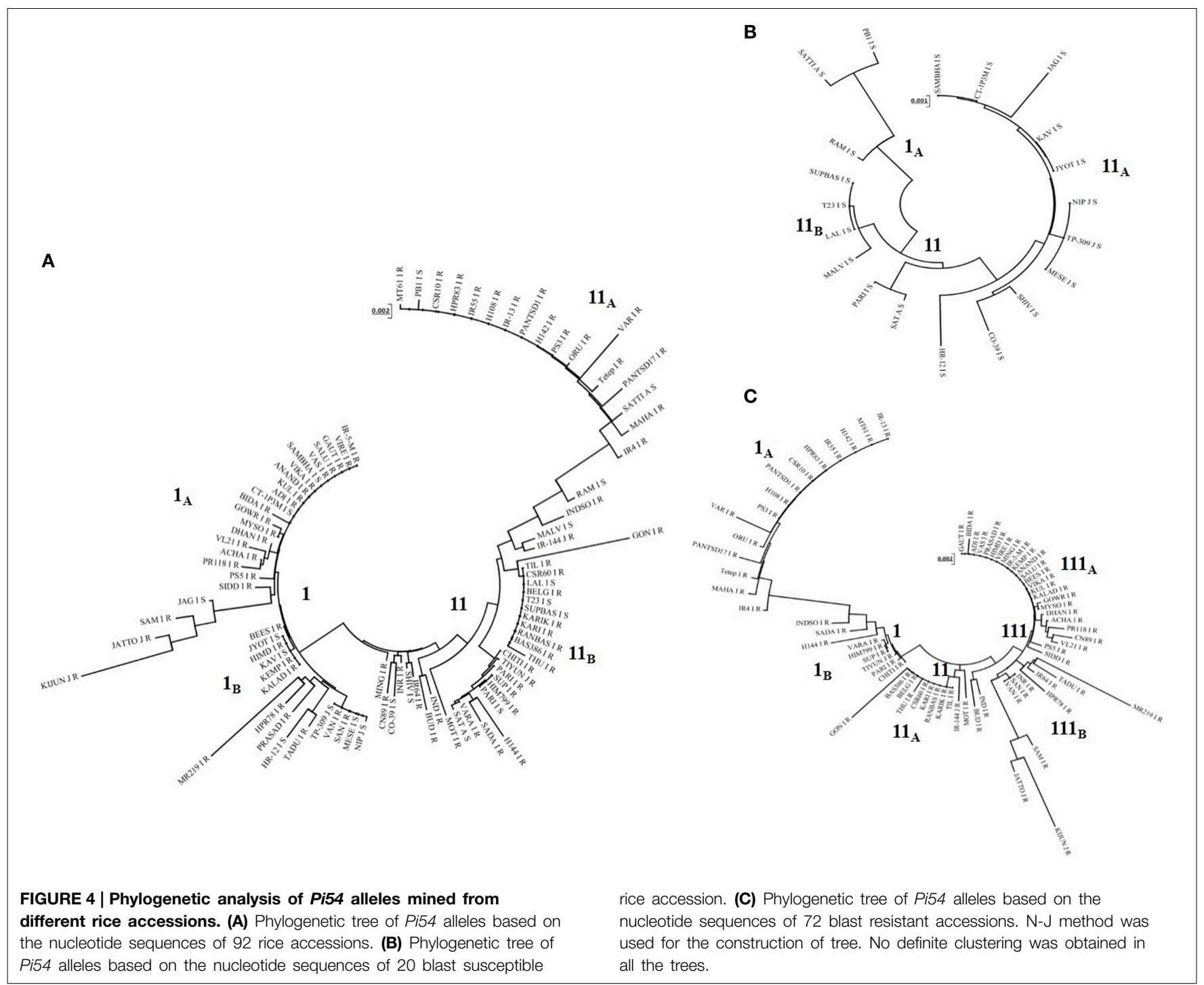

resistant rice lines. Eight rice lines showed presence of both the alleles (Table 5).

\section{Discussion}

Breeding efforts have capitalized only a fraction of the genetic diversity available to us. Food availability needs to be increased in face of intensifying demand, climate change, soil degradation, land, and water shortages. Farmers are saviors of seeds of crop species, primitive varieties (local domesticates called landraces), wild relatives of crop species (McCouch, 2013). The biodiversity present within the farmer adapted land races must be mined to discover novel sources of resistance to pests and diseases. Chromosome 11 of rice as reported, has the most associated disease resistance loci and the highest frequency of copy number variations (CNVs). Genes in most of CNVs were reported to be associated with resistance phenotype (Yu et al., 2011; Wang et al., 2014). The allelic variants of the dominant blast resistance gene, Pi54 located on chromosome 11 were prospected and variations in terms of SNPs and InDels were documented. These variations possibly might play an important role in the durability of Pi54 gene against $M$. oryzae population. In earlier studies, InDels and SNPs have shown to play a pivotal role in $R$-gene evolution through selection (Shen et al., 2006). The presence of $5 \mathrm{Mb}$ region (super locus) physically linked to $\mathrm{Pi}$-ta gene impart resistance phenotype (Jia and Martin, 2008; Lee et al., 2009). The higher frequency of SNP observed in present study might be due to the combined analysis of both landraces and cultivated species. Similarly, higher variation was also observed between $O$. sativa and $O$. rufipogon in $26 \mathrm{~kb}$ region of DNA sequence spanning 22 loci (Rakshit et al., 2007). Further in all the Pi54 alleles, transitions were more frequent than transversions. This complies with the common composition of any type of DNA, where transitions have been reported to occur at higher frequencies than transversions (Brown et al., 1982; Gojobori et al., 1982; Curtis and Clegg, 1984; Wakeley, 1996). This is in consistent with the earlier genome wide SNP discovery studies in multiple rice genotypes (Huang et al., 2009; McNally et al., 2009; Yamamoto et al., 


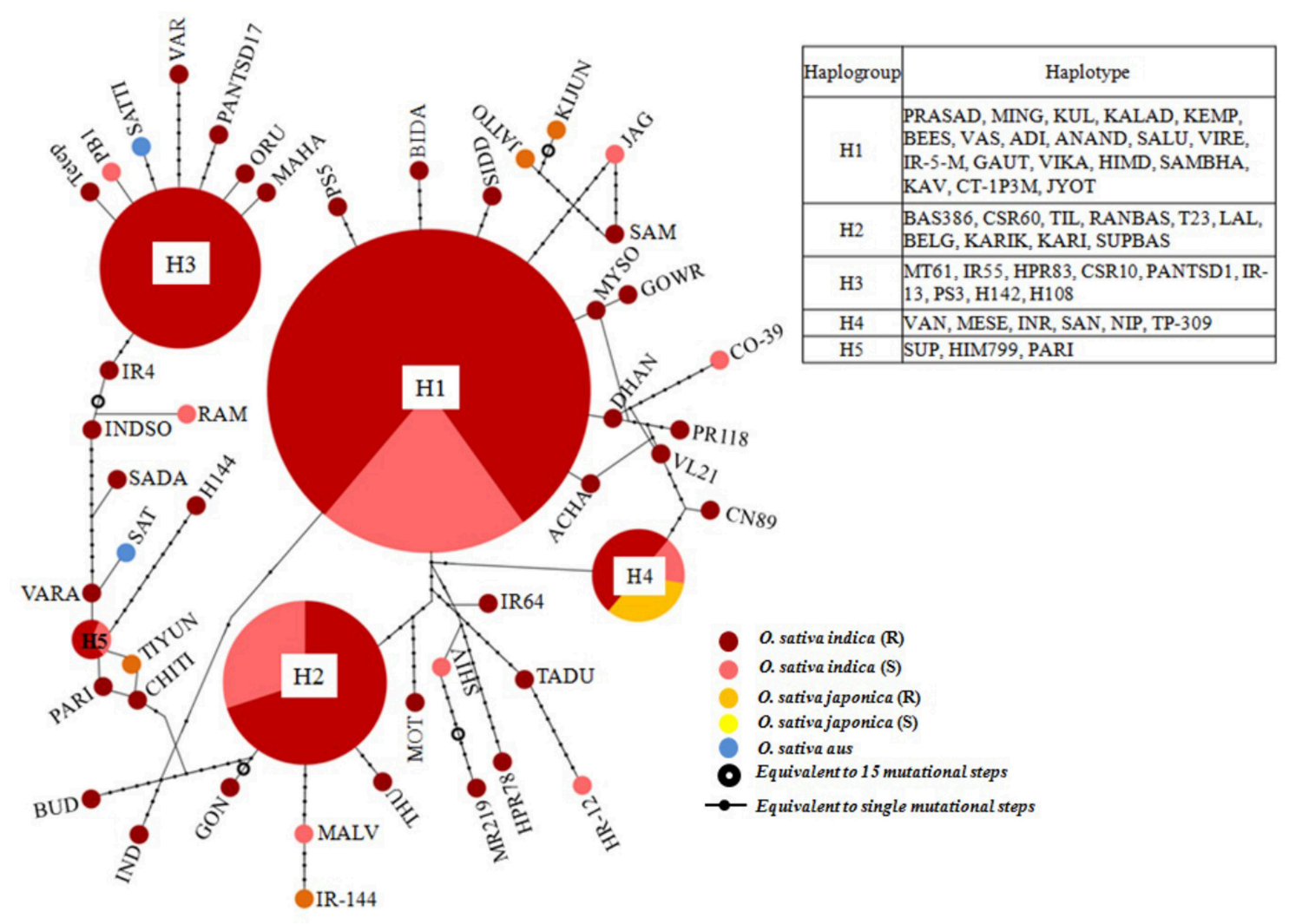

FIGURE 5 | A haplotype network based on potential SNPs of the 92 Pi54 alleles. Each group of haplotypes is shown as a solid circle, and five major haplotypes are marked in larger circles. Each branch represents a single mutational step. Branches with small solid circles indicate that there is more than a single mutational step between haplotypes. Different sizes of circles represent the different numbers of each haplotype.
TABLE 3 | Summary statistics of haplotype diversity in Pi54 alleles.

\begin{tabular}{lccc}
\hline Group & Hn & Hd & V(Hd)/SD \\
\hline All & 50 & 0.935 & $0.00027 / 0.016$ \\
Disease resistance phenotypes & 41 & 0.935 & $0.00036 / 0.019$ \\
Disease susceptible phenotypes & 14 & 0.958 & $0.00079 / 0.028$ \\
\hline
\end{tabular}

Hn, Number of Haplotypes; Hd, Haplotype diversity; V(Hd), Variance of Haplotype diversity; SD, Standard deviation of Haplotype diversity.

2010; Thakur et al., 2014). Relatively higher (70\%) frequency of transition substitutions between indica and japonica was observed in earlier studies (Feltus et al., 2004; Shen et al., 2004; International Rice Genome Sequencing Project, 2005). The present study indicates that Pi54 alleles belong to type II category (intermediate diversified), similar to other blast resistance gene Pi 9 (Yang et al., 2008; Liu et al., 2011). It is increasingly believed that percent polymorphism is directly correlated to evolutionary change (Shen et al., 2006; Yang et al., 2008). Our results suggest that intermediate level of polymorphism in the Pi54 alleles may be due to the mixed evolutionary pressure experienced by the loci during co-evolution of rice blast pathogen. Since this gene has not been transferred to cultivated varieties and might have less pressure from pathogen side.
In present study, 198 polymorphic sites were identified in the $1.5 \mathrm{~Kb}$ region of Pi54 alleles. The nucleotide diversity was high in the Pi54 alleles of resistant lines compared to the susceptible alleles. Previously, it was reported that $R$-genes experience both high and low levels of sequence diversity depending upon the locus (Yang et al., 2008). Nucleotide diversity (0.024) in $A$. thaliana was higher than the average $\pi(0.008)$ in 334 randomly distributed genomic regions due to nucleotide difference between resistant and susceptible alleles indicating that these alleles have been maintained for long period of time under natural conditions (Schmid et al., 2005). In barley, the frequency and distribution of the nucleotide diversity ranged from 0.0021 to 0.0189 for the genes associated with grain germination (Russell et al., 2004). In another study, the pattern of diversity observed was lowest in cultivated species as compared to other Oryza species (Lee et al., 2009). However, the variation at the flanking regions of the Pi-ta gene was highest in O. rufipogon (0.00355) followed by cultivated species of Oryza (Lee et al., 2011). Studies of many $R$ gene loci, such as Rpp5 in Arabidopsis thaliana and $R p 1$ in Zea mays (Noel et al., 1999; Sun et al., 2001) have revealed a high level of polymorphism between the alleles. In resistance landraces, the expression of Os11g0225100 locus was higher compared to susceptible. Even after inoculation, the resistance level in the resistant landrace increased, while it has no change 

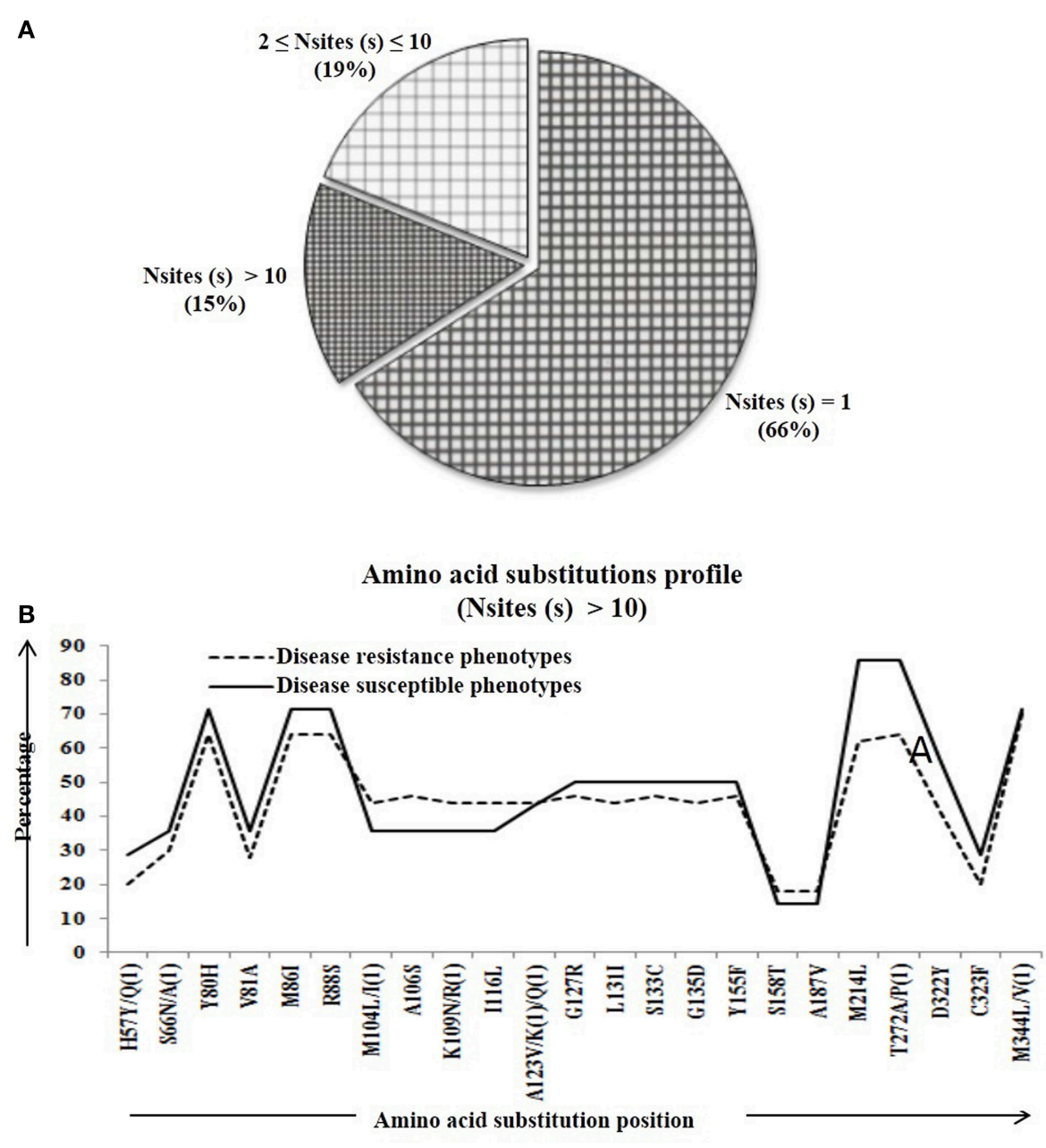

FIGURE 6 | The number of amino acid substitutions in the predicted 64 Pi54 protein. (A) Distribution of amino acid substitutions across 64 predicted proteins. (B) Substitutional profile of amino acids of disease resistant and susceptible phenotype.

in the susceptible landrace. This high diversity is interpreted as evidence for the fast evolution of these $R$ gene loci.

Phylogenetic analyses of the Pi54 alleles from susceptible lines were grouped into two major clusters, while all the resistant Pi45 orthologs were grouped into three clusters. In all the clusters and sub-clusters mixed type of grouping was obtained. However, landraces are found in all the sub-clusters corroborating the claim of higher variability and heterogeneity. This is in contrast to Pi9 alleles wherein cultivated rice along with its ancestors clustered into one group and African cultivated rice along with its ancestors grouped into separate cluster suggesting that different selection pressure has occurred in two groups during domestication and/or natural selection (Liu et al., 2011).

Important motifs identified in the translated sequences of the Pi54 alleles, i.e., N-glycosylation, phosphorylation, tyrosine sulfation, $\mathrm{N}$-myristoylation, and leucine zipper. These sites were present in variable numbers in all the Pi54 alleles except for tyrosine kinase phosphorylation site and leucine zipper. The $\mathrm{Zn}$-finger domain protein is reported responsive to wounding, stress hormones, cold, salt, submergence, heavy metals and desiccation (Vij and Tyagi, 2008). The presence of motif sites in the translated sequence indicate its role in downstream signaling of defense response genes (callose, laccase, PAL, and peroxidase), transcription factors (NAC6, Dof Zinc finger, MAD box, bZIP, and WRKY) that fortify cell wall/plasmodesmata leading to hypersensitive response, and affecting resistance reaction (Gupta et al., 2011).

In the study, fifty new haplotypes were identified from the nucleotide polymorphism of the Pi54 alleles. Interestingly, we identified one haplotype which is resistant specific (H_3). Small number of haplotypes was detected previously within the gene pool of cultivated (H. vulgare) barley. In Hordeum species, the total number of haplotypes identified (46) in H. spontaneum almost double from those detected in $H$. vulgare (Russell et al., 2004). Similarly, 16 haplotypes were identified from nucleotide polymorphism of fiftyone Pi-ta alleles (Huang et al., 2008). In another study, $53 \mathrm{Pi}$-ta haplotypes were identified from the nucleotide polymorphism of 229 rice accessions belonging to 

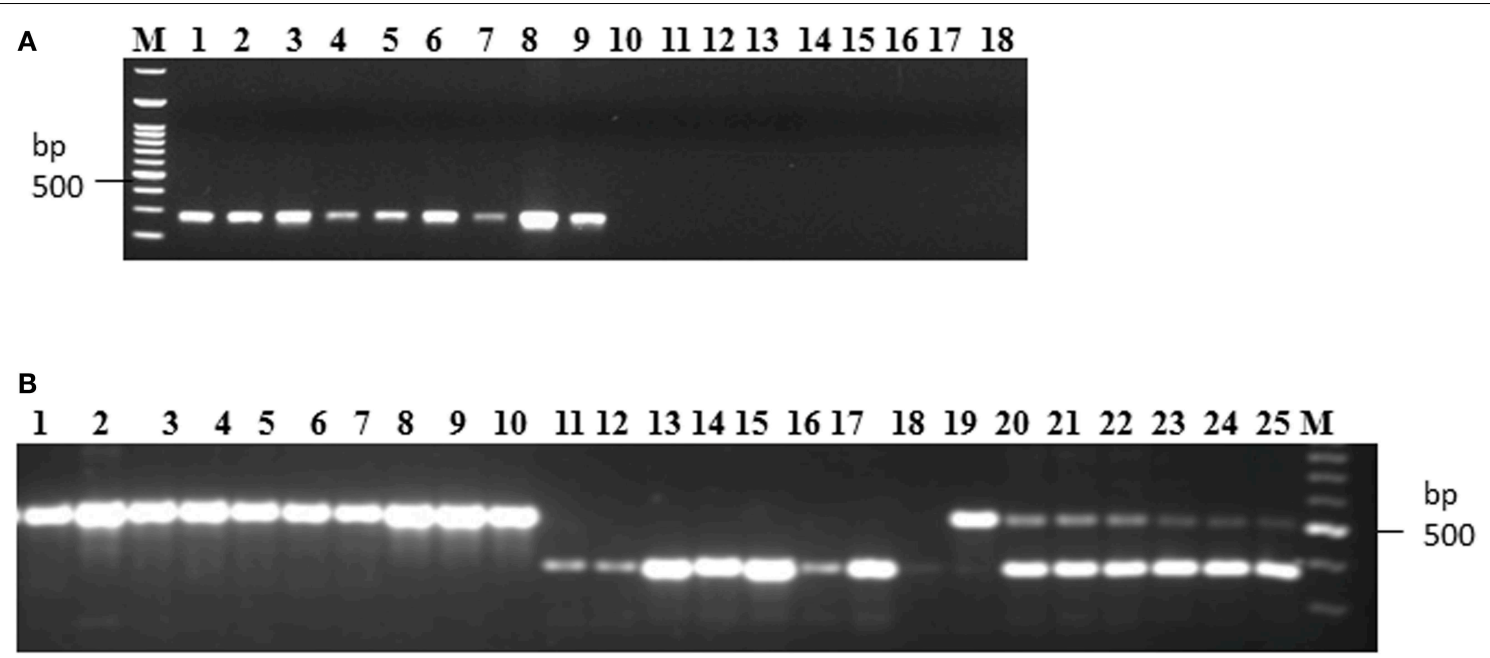

FIGURE 7 | PCR amplification of rice lines with the dominant and co-dominant PCR marker. (A) PCR amplification with the dominant marker (D163_F and D163_R) in 18 rice lines. Lanes 1-9: presence of band in rice lines (Acharmati, Aditya, Ananda, Beesginsali, Bidarlocal-2, Dhanaprasad, Gautam, Himdhan, and Pusa sugandh 5); lanes 10-18: absence of band in rice lines.(HR-12, TP-309, Co-39, Nipponbare, Shiva, Satti, Pusa basmati-1, Ram Jawain-100, and Sathia-2) (B) PCR amplification with the co-dominant marker (C144_F and C144_R) in 26 rice lines. bp- base pair; M$100 \mathrm{bp}$ molecular marker. Lanes 1-10: presence of susceptible band (CO-39, HR-12, CT-10006-7-2M-5-1P3M, Jyoti, Kavali kannu, Mesebatta, Nipponbare, Samba mahsuri, Shiva, Taipei-309); lanes 11-18: presence of resistant band (Tetep, Budda, Chiti zhini, CSR 10, Gonrra bhog, Himalya 799, Pusa Sugandh 3, Ranbir basmati, Sadabahar); lanes 19-25: presence of both the bands (Belgaum basmati, CSR-60, HLR-142, Indrayani, IRAT-144, Kariya).
TABLE 4 | List of rice accessions distinguishable based on dominant marker.

\begin{tabular}{lll}
\hline & Homozygous RR & Homozygous rr \\
\hline Acharmati & Pusa sugandh 5 & Mesebatta \\
Aditya & Salumpikit & HR-12 \\
Ananda & Samleshwari & TP-309 \\
Beesginsali & Siddasala & Co-39 \\
Bidarlocal-2 & V L Dhan 21 & Nipponbare \\
Dhanaprasad & Vasanesanna batta & Shiva \\
Gautam & Vikash & Satti \\
Himdhan & Virendra & Pusa basmati-1 \\
IRBB-4 & & Ram Jawain-100 \\
IRBLB-BIRBLB-5-M & & Sathia-2 \\
Kala Dhan & & Lalan kanda \\
Kulanji pille & & Superbasmati \\
Mingola & & Parijat \\
Mysore mallige & & Malviya dhan \\
& & T23 \\
\hline
\end{tabular}

seven Oryza species. These findings highlighted the importance of analysis and utilization of haplotypes from landraces and related wild species for crop improvement (Lee et al., 2009).

Balancing and purifying selection have been observed for the evolution of $R$-genes. The value of Tajima's $D$ was negative in the entire coding region $(-1.03898)$ and LRR domain $(-1.70363)$ indicating purifying selection in the CDS and LRR regions. Similar, values were also reported for $P i$-ta alleles of O. rufipogon and $P i 9$ alleles of five Oryza species (AA genome) (Lee et al., 2009;
TABLE 5 | List of rice accessions distinguishable based on co-dominant marker.

\begin{tabular}{|c|c|c|c|}
\hline \multicolumn{2}{|c|}{ Homozygous (RR) } & \multirow{2}{*}{$\begin{array}{l}\text { Homozygous (rr) } \\
\text { CO-39 }\end{array}$} & \multirow{2}{*}{$\begin{array}{l}\text { Heterozygous (Rr) } \\
\text { Belgaum basmati }\end{array}$} \\
\hline Budda & Mahamaya & & \\
\hline Chiti zhini & MTU-1061 & $\begin{array}{l}\text { CT-10006-7- } \\
\text { 2M-5-1P3M }\end{array}$ & CSR-60 \\
\hline CSR 10 & Pant sankar dhan 1 & $\mathrm{HR}-12$ & HLR-142 \\
\hline Gonrra bhog & Pant sugandh dhan 17 & Jyoti & Indrayani \\
\hline Himalya 799 & Tetep & Kavali kannu & IRAT-144 \\
\hline HLR-108 & Pusa Sugandh 3 & Mesebatta & Kariya \\
\hline HLR-144 & Ranbir basmati & Nipponbare & Orugallu \\
\hline HPR 2083 & Sadabahar & Samba mahsuri & Parimala kalvi \\
\hline HPR-2178 & Suphala & Shiva & \\
\hline Indira sona & Thule atte & Taipei-309 & \\
\hline IRBB 55 & Tilak chandan & & \\
\hline IRBB-13 & Tiyun & & \\
\hline IRBB-4 & Varalu & & \\
\hline Kari kantiga & Varun dhan & & \\
\hline
\end{tabular}

Liu et al., 2011). Our analyses implicate selection pressure high on both CDS and LRR domains of resistant lines, in contrast to the LRR domain of susceptible rice lines. Elucidation of the selection mechanism acting on the domains could help to design new crop improvement strategies for the future.

In the LRR region of the Pi54 alleles of different groups, the value of $\mathrm{k}_{\mathrm{a}} / \mathrm{k}_{\mathrm{s}}>1.0$ implying positive directional selection might have favored amino acid substitution in the region. Similar results were also obtained in $\mathrm{Piz}(t)$ alleles of Indian landraces 
of diverse locations (Thakur et al., 2013b). In contrast, the LRR regions encoded by $P i-k m 1$ and $P i-k m 2$ blast resistance genes were highly conserved (Ashikawa et al., 2010). Importantly, LRRs have direct interacting roles with effector proteins (Young and Innes, 2006). Most isolated $R$-genes encode proteins possessing LRR domain, of which the majority also contains a NBS domain (Sharma et al., 2012). Higher level of polymorphism in the LRR region as obtained in case of Pi54 gene is thought to be involved in the recognition of effector proteins, and consequently the evolutionary pressure on the host by virulent $M$. oryzae races results in high variability in LRR domain. The LRR regions of many Arabidopsis $R$ genes have $\mathrm{k}_{\mathrm{a}} / \mathrm{k}_{\mathrm{s}}$ ratios $>1$, suggesting that these $R$ genes have evolved under positive selection pressure (Bergelson et al., 2001). Two basic strategies have evolved for an $\mathrm{R}$ protein to recognize a pathogen effector (which is also called avirulence (Avr) factor): direct physical interaction and indirect interaction via. association with other host proteins targeted by the Avr factor (Xiao et al., 2008). It has also been reported that variation for disease resistance is maintained by frequencydependent selection, even though there is a fitness cost associated with the maintenance of $R$ genes in the absence of their matching Avr (Stahl et al., 1999). Flax $L$ genes and their matching Avr genes in flax rust undergo strong diversifying selection, suggesting direct interaction (Dodds et al., 2006). However, in case of $A$. thaliana indirect interaction between $R P M 1$ and $A v r B$, in which the RIN4 protein acts as a target for binding to $A v r B$, and the AvrB-induced phosphorylation of RIN4 then activates RPM1 has been reported as balancing selection (Mackey et al., 2002).

Development of allele specific functional markers holds the key for marker assisted selection. These functional markers based on genic Pi54 InDels can be applicable in MAS for blast resistance breeding programme. Absence of diagnostic bands in resistant/susceptible cultivars might be because of genetic recombination during meiotic cell cycle. However, the present study extends the repertoire of functional markers toward screening of genotypes. Similar functional InDel-based marker has been reported to be developed for blast resistance gene Pikm (Costanzo and Jia, 2010). The sequence of nine blast resistance genes was used for the development of functional markers based on InDels (Hayashi et al., 2006). However, allele specific markers are not known for blast resistance gene Pi54, hence the markers developed in this study would be of great significance to the breeders. Increasing efforts to clone more resistance genes worldwide will accelerate the development of more dominant resistance gene based markers for molecular breeding, thereby accelerating introduction of durable, broadspectrum blast resistant genes into widely adapted high yielding rice cultivars.

From the above discussion, we conclude that the nucleotide variation was high in the LRR domain of all the Pi54 alleles cloned and characterized in this study. In disease resistant alleles, selection pressure was high in LRR domain and CDS region whereas in susceptible counterpart selection pressure exerted only in the LRR domain. It was also evident that LRR domain of Pi54 alleles was diversified because of high selection pressure. The co-dominant and dominant functional markers developed in the present study can be used in marker-assisted breeding programs aimed at improvement of blast resistance in elite rice cultivars. The diversity information based on genetic structure is an extremely important pre-breeding material in selecting parents for intra- and inter- group crosses to broaden the genetic base of modern rice cultivars. This study helps understand the extent of variability present in the landraces and cultivated varieties of rice that can be employed in future for selection of better alleles and their utilization in resistant breeding programmes.

\section{Author Contributions}

Conceived and designed the experiments: TRS. Performed the experiments and analyzed data: ST. Contributed materials/analysis tools: RR, MV, SP, DC, AD, NS, AS, UD, and PS. Wrote the paper: TRS, ST, and AD.

\section{Acknowledgments}

TRS is thankful to the National Agricultural Innovation Project (NAIP) (C4/C1071), ICAR, for financial support. TRS is thankful to the Department of Science and Technology, Govt. of India for JC Bose National Fellowship. The authors are thankful to the Officer in Charge, National Phytotron Facility, Indian Agricultural Research Institute, New Delhi, for providing basic facilities for growing and maintaining Indian local landraces.

\section{Supplementary Material}

The Supplementary Material for this article can be found online at: http://journal.frontiersin.org/article/10.3389/fpls.2015. 00345/abstract

Figure S1 | Haplotype network based on 187 potential SNPs of the Pi54 resistant alleles. Each group of haplotypes is shown as a solid circle, and five major haplotypes are marked in larger circles. Each branch represents a single mutational step. Branches with small solid circles indicate that there is more than a single mutational step between haplotypes. Different sizes of circles represent the different numbers of each haplotype.

Figure S2 | Haplotype network based on 97 potential SNPs of the Pi54 susceptible alleles. Each group of haplotypes is shown as a solid circle, and four major haplotypes are marked in larger circles. Each branch represents a single mutational step. Branches with small solid circles indicate that there is more than a single mutational step between haplotypes. Different sizes of circles represent the different numbers of each haplotype.

Figure S3 | Analysis of ZnF domain of 61 Pi54 proteins. Arrows indicate that the $\mathrm{ZnF}$ doamain was not predicted inspite of the sequence of the $\mathrm{ZnF}$ in the Pi54 proteins. Single amino acid substitution in two Pi54 proteins has been encircled.

Figure S4 | Phylogenetic tree of LRR domain of 64 Pi54 protein.

Neighbor-Joining method was used for the construction of tree. Definite clustering was not obtained in all the tees. 


\section{References}

Ashikawa, I., Wu, J., Matsumoto, T., and Ishikawa, R. (2010). Haplotype diversity and molecular evolution of the rice Pikm locus for blast resistance. J. Gen. Plan. Pathol. 76, 37-42. doi: 10.1007/s10327-009-0213-x

Bergelson, J., Kreitman, M., Stahl, E. A., and Tian, D. (2001). Evolutionary dynamics of plant $R$-genes. Science 292, 2281-2285. doi: $10.1126 /$ science. 1061337

Bonmann, J. M., Dedios, T. V., and Khin, M. M. (1986). Physiologic specialization 718 of Pyricularia oryzae in Phillippines. Plant Dis. 70, 767-769. doi: 10.1094/PD-70-767

Brown, W. M., Prager, E. M., Wang, A., and Wilson, A. C. (1982). Mitochondrial DNA sequences of primates, tempo and mode of evolution. J. Mol. Evol. 18, 225-239. doi: 10.1007/BF01734101

Clement, M., Posada, D., and Crabdall, K. (2000). TCS: a computer program to estimate gene genealogies. Mol. Ecol. 9, 1657-1660. doi: 10.1046/j.1365294x.2000.01020.x

Costanzo, S., and Jia, Y. (2010). Sequence variation at the rice blast resistance gene Pi-km locus: implications for the development of allele specific markers. Plant Sci. 178, 523-530. doi: 10.1016/j.plantsci.2010.02.014

Curtis, S. E., and Clegg, M. T. (1984). Molecular evolution of chloroplast DNA sequences. Mol. Biol. Evol. 1, 291-301.

Das, A., Soubam, D., Singh, P. K., Thakur, S., Singh, N. K., and Sharma, T. R. (2012). A novel blast resistance gene, Pi54rh cloned from wild species of rice, Oryza rhizomatis confers broad spectrum resistance to Magnaporthe oryzae. Funct. Integr. Genomics 12, 215-228. doi: 10.1007/s10142-012-0284-1

Dodds, P. N., Lawrence, G. J., Catanzariti, A., Teh, T., Wang, C., Ayliffe, M. A., et al. (2006). Direct protein interaction underlies gene-for- gene specificity and coevolution of the flax resistance genes and flax rust avirulence genes. Proc. Natl. Acad. Sci. U.S.A. 103, 8888-8893. doi: 10.1073/pnas.0602577103

Ewing, B., and Green, P. (1998). Base-calling of automated sequencer traces using Phred II error probabilities. Genome Res. 8, 186-194.

Felsenstein, J. (1985). Confidence limits on phylogenies: an approach using the bootstrap. Evolution 39, 783-791. doi: 10.2307/2408678

Feltus, A., Wan, J., Schulze, S. R., Estill, J. C., Jiang, N., and Paterson, A. H. (2004). An SNP resource for rice genetics and breeding based on subspecies indica and japonica genome alignments. Genome Res. 14, 1812-1819. doi: 10.1101/gr.2479404

Geng, X. S., Yang, M. Z., Huang, X. Q., Cheng, Z. Q., Fu, J., Sun, T., et al. (2008). Cloning and analyzing of rice blast resistance gene $\mathrm{Pi}_{-} \mathrm{ta}^{+}$allele from Jinghong erect type of common wild rice (Oryza rufipogon Griff) in Yunnan. Yi Chuan 30, 109-114. doi: 10.3724/SP.J.1005.2008.00109

Gojobori, T., Li, W. H., and Graur, D. (1982). Patterns of nucleotide substitution in pseudogenes and functional genes. J. Mol. Evol. 18, 360-369. doi: 10.1007/BF01733904

Gupta, S. K., Rai, A. K., Kanwar, S. S., Chand, D., Singh, N. K., and Sharma, T. R. (2011). The single functional blast resistance gene Pi54 activates a complex defense mechanism in rice. J. Exp. Bot. 63, 757-772. doi: 10.1093/jxb/err297

Gupta, S. K., Rai, A. K., Kanwar, S. S., and Sharma, T. R. (2012). Comparative analysis of zinc finger proteins involved in plant disease resistance. PLOS ONE 7:e42578. doi: 10.1371/journal.pone.0042578

Hayashi, K., Hashimoto, N., Daigen, M., and Ashikawa, I. (2004). Development of PCR-based SNP markers for rice blast resistance genes at the Piz locus. Theor. Appl. Genet. 108, 1212-1220. doi: 10.1007/s00122-003-1553-0

Hayashi, K., Yoshida, H., and Ashikawa, I. (2006). Development of PCR-based allele-specific and InDel marker sets for nine rice blast resistance genes. Theor. Appl. Genet. 113, 251-260. doi: 10.1007/s00122-006-0290-6

Huang, C. L., Hwang, S. Y., Chiang, Y. C., and Lin, T. P. (2008). Molecular evolution of the Pi-ta gene resistant to rice blast in wild rice (Oryza rufipogon). Genetics 179, 1527-1538. doi: 10.1534/genetics.108.089805

Huang, X., Feng, Q., Qian, Q., Zhao, Q., Wang, L., Wang, A., et al. (2009). High-throughput genotyping by whole-genome resequencing. Genome Res. 19, 1068-1076. doi: 10.1101/gr.089516.108

International Rice Genome Sequencing Project. (2005). The map-based sequence of the rice genome. Nature 436, 793-800. doi: 10.1038/nature03895

Jia, Y., Liu, G., Costanzo, S., Lee, S., and Dai, Y. (2009). Current progress on genetic interactions of rice with rice blast and sheath blight fungi. Front. Agric. China 3:6. doi: 10.1007/s11703-009-0062-6
Jia, Y., and Martin, R. (2008). Identification of a new locus $P \operatorname{tr}(t)$ required for rice blast resistance gene Pi-ta-mediated resistance. Mol. Plant Microbe Interact. 21, 396-403. doi: 10.1094/MPMI-21-4-0396

Larkin, M. A., Blackshields, G., Brown, N. P., Chenna, R., McGettigan, P. A., McWilliam, H., et al. (2007). Clustal W and Clustal X version 2.0. Bioinformatics 23, 2947-2948. doi: 10.1093/bioinformatics/btm404

Lee, S., Costanzo, S., Jia, Y., Olsen, K. M., and Caicedo, A. L. (2009). Evolutionary dynamics of the genomic region around the blast resistance gene Pi-ta in AA genome Oryza species. Genetics 183, 1315-1325. doi: 10.1534/genetics.109.108266

Lee, S., Jia, Y., Jia, M., Gealy, D. R., and Olsen, K. M. (2011). Molecular evolution of the rice blast resistance gene $P$ - $t a$ in invasive weedy rice in the USA. PLoS ONE 6:e26260. doi: 10.1371/journal.pone.0026260

Liu, J., Hu, Y., Ning, Y., Jiang, N., Wu, J., Xiao, Y., et al. (2011). Genetic variation and evolution of the Pi9 blast resistance locus in the AA genome Oryza species. J. Plant Biol. 54, 294-302. doi: 10.1007/s12374-011-9166-7

Mackey, D., Holt, B. F., Wiig, A., and Dangl, J. L. (2002). RIN4 interacts with Pseudomonas syringae type III effector molecules and is required for RPM1mediated resistance in Arabidopsis. Cell 108, 743-754. doi: 10.1016/S00928674(02)00661-X

McCouch, S. (2013). Feeding the future. Nature 499, 23-24. doi: 10.1038/499023a

McNally, K. L., Childs, K. L., Bohert, R., Davidson, R. M., Zhao, K., Ulat, B. J., et al. (2009). Genome-wide SNP variation reveals relationships among landraces and modern varieties of rice. Proc. Natl. Acad. Sci. U.S.A. 106, 12273-12278. doi: 10.1073/pnas.0900992106

Murray, M. G., and Thompson, W. F. (1980). Rapid isolation of high molecular weight plant DNA. Nucl. Acids. Res. 8, 4321-4325. doi: 10.1093/nar/8.19.4321

Nei, M. (1987). Molecular Evolutionary Genetics. New York, NY: Columbia University Press.

Noel, L., Moores, T. L., van der Biezen, E. A., Parniske, M., Daniels, M. J., Parker, J. E., et al. (1999). Pronounced intra specific haplotype divergence at the RPP5 complex disease resistance locus of Arabidopsis. Plant Cell 11, 2099-2111. doi: $10.1105 /$ tpc.11.11.2099

Rai, A. K., Kumar, S. P., Gupta, S. K., Gautam, N., Singh, N. K., and Sharma, T. R. (2011). Functional complementation of rice blast resistance gene $P i-k^{h}$ (Pi54). conferring resistance to diverse strains of Magnaporthe oryzae. J. Plant Biochem. Biotech. 20, 55-65. doi: 10.1007/s13562-010-0026-1

Rakshit, S., Rakshit, A., Matsumura, H., Takahashi, Y., Hasegawa, Y., Ito, A., et al. (2007). Large scale DNA polymorphism study of Oryza sativa and O. rufipogon reveals the origin and divergence of Asian rice. Theor. Appl. Genet. 114, 731-743. doi: 10.1007/s00122-006-0473-1

Ram, S. G., Thiruvengadam, V., and Vinod, K. K. (2007). Genetic diversity among cultivars, land races and wildr elatives of rice as revealed by microsatellite markers. J. Appl. Genet. 48, 337-345. doi: 10.1007/BF03195230

Rozas, J., Sánchez-DelBarrio, J. C., Messeguer, X., and Rozas, R. (2003). DnaSP, DNA polymorphism analyses by the coalescent and other methods. Bioinformatics 19, 2496-2497. doi: 10.1093/bioinformatics/btg359

Rozen, S., and Skaletsky, H. (2000). Primer 3 on the WWW for general users for biologist programmers. Methods Mol. Biol. 132, 365-386.

Russell, J., Booth, A., Fuller, J., Harrower, B., Hedley, P., Machray, G., et al. (2004). A comparison of sequence-based polymorphism and haplotype content in transcribed and anonymous regions of the barley genome. Genome 47, 389-398. doi: $10.1139 / \mathrm{g} 03-125$

Saitou, N., and Nei, M. (1987). The neighbor-joining method: anew method for reconstructing phylogenetic trees. Mol. Biol. Evol. 4, 406-425.

Schmid, M., Davison, T. S., Henz, S. R., Pape, U. J., Demar, M., Vingron, M., et al. (2005). A gene expression map of Arabidopsis thaliana development. Nat. Genet. 37, 501-506. doi: 10.1038/ng1543

Shang, J., Tao, Y., Chen, X., Zou, Y., Lei, C., Wang, J., et al. (2009). Identification of a new rice blast Resistance gene, Pid3, by genome wide comparison of paired Nucleotide-Binding Site-Leucine-Rich Repeat genes and their pseudogene alleles between the two sequenced rice genomes. Genetics 182, 1303-1311. doi: 10.1534/genetics.109.102871

Sharma, T. R., Das, A., Thakur, S., and Jalali, S. (2014). Recent understanding on structure, function and evolution of plant disease resistance genes. Proc. Indian Nat. Sci. Acad. 1, 83-93. doi: 10.16943/ptinsa/2014/v80i1/55088

Sharma, T. R., Madhav, M. S., Singh, B. K., Shanker, P., Jana, T. K., Dalal, V., et al. (2005a). High-resolution mapping., cloning., and molecular characterization of 
the Pi-k $k^{h}$ gene of rice, which confers resistance to Magnaporthe grisea. Mol. Genet. Genomics 274, 569-578. doi: 10.1007/s00438-005-0035-2

Sharma, T. R., Rai, A. K., Gupta, S. K., and Singh, N. K. (2010). Broad-spectrum Blast Resistance gene Pi- $k^{h}$ cloned from rice line Tetep designated Pi54. J. Plant Biochem. Biotechnol. 191, 87-89. doi: 10.1007/BF03323441

Sharma, T. R., Rai, A. K., Gupta, S. K., Vijayan, J., Devanna, B. N., and Ray, S. (2012). Rice blast management through host-plant resistance: retrospect and prospects. Agri. Res. 1, 37-52. doi: 10.1007/s40003-011-0003-5

Sharma, T. R., Shanker, P., Singh, B. K., Jana, T. K., Madhav, M. S., Gaikward, $\mathrm{K}$, et al. (2005b). Molecular mapping of rice blast resistance gene Pi$k^{h}$ in rice variety Tetep. J. Plant Biochem. Biotechnol. 14, 127-133. doi: $10.1007 / \mathrm{BF} 03263240$

Shen, J. H., Araki, L., Chen, J. Q., and Chen Tian, D. (2006). Unique evolutionary mechanism in $R$-genes under the presence/absence polymorphism in Arabidopsis thaliana. Genetics 172, 1243-1250. doi: 10.1534/genetics.105.047290

Shen, Y. J., Jiang, H., Jin, J. P., Zhang, Z. B., Xi, B., He, Y. Y., et al. (2004). Development of genome-wide DNA polymorphism database for map-based cloning of rice genes. Plant Physiol. 135, 1198-1205. doi: 10.1104/pp.103.038463

Singh, A. K., Gopalakrishnan, S., Singh, V. P., Prabhu, K. V., Mohapatra, T., Singh, N. K., et al. (2011). Marker assisted selection: a paradigm shift in Basmati breeding. Indian J. Genet. 71, 1-9.

Solovyev, V., Kosarev, P., Seledsov, I., and Vorobyev, D. (2006). Automatic annotation of eukaryotic genes., pseudogenes and promoters. Genome Biol. 7(Suppl. 1), S10. doi: 10.1186/gb-2006-7-s1-s10

Stahl, E. A., Dwyer, G., Mauricio, R., Kreitman, M., and Beregelson, J. (1999). Dynamics of disease resistance polymorphism at the Rpm1 locus of Arabidopsis. Nature 400, 667-671. doi: 10.1038/23260

Sun, Q., Collins, N. C., Ayliffe, M., Smith, S. M., Drake, J., Pryor, T., et al. (2001). Recombination between paralogues at the $R p 1$ rust resistance locus in maize. Genetics 158, 423-438.

Tajima, F. (1989). Statistical method for testing the neutral mutation hypothesis by DNA polymorphism. Genetics 123, 585-595.

Tamura, K., Dudley, J., Nei, M., and Kumar, S. (2007). MEGA4: molecular evolutionary genetics analysis (MEGA) software version 4.0. Mol. Biol. Evol. 24, 1596-1599. doi: 10.1093/molbev/msm092

Tamura, K., Nei, M., and Kumar, S. (2004). Prospects for inferring very large phylogenies by using the neighbor-joining method. Proc. Natl. Acad. Sci. U.S.A. 101, 11030-11035. doi: 10.1073/pnas.0404206101

Templeton, A. R., Crandal, A. K., and Sing, C. F. (1992). A cladistic analysis of phenotypic associations with haplotypes inferred from restriction endonuclease mapping and DNA sequence data III Cladogram estimation. Genetics 132, 619-633.

Thakur, S., Gupta, Y. K., Singh, P. K., Rathour, R., Variar, M., Prashanthi, S. K., et al. (2013a). Molecular diversity in rice blast resistance gene Pi-ta makes it highly effective against dynamic population of Magnaporthe oryzae. Funct. Integr. Genomics 13, 309-322. doi: 10.1007/s10142-013-0325-4

Thakur, S., Singh, P. K., Rathour, R., Variar, M., Prashanthi, S. K., Gopalakrishnan, S., et al. (2014). Genotyping and development of single-nucleotide polymorphism (SNP) markers associated with blast resistance genes in rice using GoldenGate assay. Mol. breeding 34, 1449-1463. doi: 10.1007/s11032-014-0129-9
Thakur, S., Singh, P. K., Rathour, R., Variar, M., Prashanthi, S. K., Singh, A. K., et al. (2013b). Positive selection pressure on rice blast resistance allele Piz$t$ makes it divergent in Indian land races. J. Plant Interact. 8, 34-44. doi: $10.1080 / 17429145.2012 .721523$

Vij, S., and Tyagi, A. K. (2008). A20/AN1 zinc-finger domain-containing proteins in plants and animals represent common elements in stress response. Funct. Integr. Genomics 8, 301-307. doi: 10.1007/s10142-008-0078-7

Wakeley, J. (1996). The excess of transitions among nucleotide substitutions: new methods of estimating transition bias underscore its significance. Tree 11, 158-163. doi: 10.1016/0169-5347(96)10009-4

Wang, C., Yang, Y., Yuan, X., Xu, Q., Feng, Y., Yu, H., et al. (2014). Genome-wide association study of blast resistance in indica rice. BMC Plant Biol. 14:6. doi: 10.1186/s12870-014-0311-6

Wang, X., Jia, Y., Shu, Q. Y., and Wu, D. (2008). Haplotype diversity at the Pi-ta locus in cultivated rice and its wild relatives. Phytopathology 98, 1305-1311. doi: 10.1094/PHYTO-98-12-1305

Xiao, S., Wang, W., and Yang, X. (2008). “Evolution of resistance genes in plans," in Innate Immunity of Plants, Animals and Human, 1st Edn., ed H. Heine (Berlin; Hidelberg: Springer), 1-25.

Yamamoto, T., Nagasaki, H., Yonemaru, J., Ebana, K., Nakajima, M., Shibaya, T., et al. (2010). Fine definition of the pedigree haplotypes of closely related rice cultivars by means of genome-wide discovery of single-nucleotide polymorphisms. BMC Genomics 11:267. doi: 10.1186/1471-2164-11-267

Yang, M. Z., Cheng, Z. Q., Chen, S. N., Qian, J., Xu, L. L., and Huang, X. Q. (2007). A rice blast resistance genetic resource from wild rice in Yunnan, China. J. Plant Physiol. Mol. Biol. 33, 589-595.

Yang, S., Gu, T., Pan, C., Feng, Z., Ding, J., Hang, Y., et al. (2008). Genetic variation of NBS-LRR class resistance genes in rice lines. Theor. Appl. Genet. 16, 165-177. doi: 10.1007/s00122-007-0656-4

Yoshida, K., and Miyashita, N. T. (2009). DNA polymorphism in the blast disease resistance gene $\mathrm{Pi}$-ta of the wild rice Oryza rufipogon and its related species. Genes Genet. Syst. 84, 121-136. doi: 10.1266/ggs.84.121

Young, B. J. D., and Innes, R. W. (2006). Plant NBS-LRR proteins in pathogen sensing and host defense. Nat. Immunol. 7, 1243-1249. doi: 10.1038/ni1410

Yu, P., Wang, C., Xu, Q., Feng, Y., Yuan, X., Yu, H., et al. (2011). Detection of copy number variations in rice using array-based comparative genomic hybridization. BMC Genomics 12:372. doi: 10.1186/1471-2164-12-372

Zhai, C., Lin, F., Dong, Z., He, X., Yuan, B., Zeng, X., et al. (2011). The isolation and characterization of $P i k$, a rice blast resistance gene which emerged after rice domestication. New Phytol. 189, 321-334. doi: 10.1111/j.14698137.2010.03462.x

Conflict of Interest Statement: The authors declare that the research was conducted in the absence of any commercial or financial relationships that could be construed as a potential conflict of interest.

Copyright (C) 2015 Thakur, Singh, Das, Rathour, Variar, Prashanthi, Singh, Singh, Chand, Singh and Sharma. This is an open-access article distributed under the terms of the Creative Commons Attribution License (CC BY). The use, distribution or reproduction in other forums is permitted, provided the original author(s) or licensor are credited and that the original publication in this journal is cited, in accordance with accepted academic practice. No use, distribution or reproduction is permitted which does not comply with these terms. 